\title{
The Hudson-Stahli Line I: An Epidemiological Study
}

\author{
GEOFFREY E. ROSE and MICHAEL J. LAVIN \\ London
}

\begin{abstract}
Summary
The overall prevalence of Hudson-Stahli line in a group of 550 subjects was 65 per cent with bilateral involvement and a further 4 per cent with unilateral involvement; analysis of two subgroups, with either blue/grey iris colour or with brown/green colour, suggested that the incidence is slightly higher in the latter group, particularly in the third to fifth decades. Irrespective of iris colour, the incidence rises with age.
\end{abstract}

Both the length and the density of the line increase with age. For a given age, brown/green eyes have longer lines than blue/green eyes, but similar densities. Concordance of length and density between the right and left eyes of a pair is seen in about 80 per cent of subjects.

The Hudson-Stahli line is a brown discolouration occurring in the epithelium of the inferior cornea, first described in $1911 .{ }^{1}$ Although it and other epithelial iron lines appear to be the result of epithelial ferritin deposition, ${ }^{2.3}$ the origin of this and the other epithelial iron lines remains unclear and a variety of explanations have been offered. ${ }^{2.3 .4 .5 .6} \mathrm{We}$ assessed the Hudson-Stahli line in a group of patients in an attempt to define more accurately its characteristics. In view of reports implicating limbal melanin in the genesis of the Hudson-Stahli line, ${ }^{7}$ we also studied the relationship between eye colour and the line.

\footnotetext{
Material and Methods

The eyes of 550 subjects attending an Ophthalmic Accident and Emergency department were examined by slit-lamp biomicroscopy for the presence of Hudson-Stahli lines; excluded from the study were patients with corneal disease, those on long-term ocular medication and contact lens wearers. Using direct and retro-illumination with white light only, the length and density of the lines (when present) were estimated and notes made of the position and configuration of the line.
}

The length of the line was estimated in relation to the maximum horizontal corneal diameter, giving one of three categories-less than one-quarter of corneal diameter $\left(<\frac{1}{4}\right)$, between one-quarter and one-half of the diameter $\left(\frac{1}{4}-\frac{1}{2}\right)$ and length greater than one-half $\left(>\frac{1}{2}\right)$; a separate category for greater than three-quarters of the corneal diameter was excluded because the usual position of the line (in the lower part of the cornea) precludes any line from being as long as the complete horizontal corneal diameter.

The density of the line was also judged to one of three categories: Those lines barely visible with slitlamp biomicroscopy ('faint', grade 1), those lines readily visible with slit-lamp biomicroscopy but barely visible by macroscopic examination ('moderate', grade 2) and those lines clearly defined on macroscopic and microscopic examination ('dense', grade 3).

To allow a semi-quantitative comparison of the properties of the Hudson-Stahli line in different groups of eyes, the arbitrary gradings for length and density were each given a value from 0 to 3 . In addition, an overall 'length/density' combined score was calculated for each cornea, this being defined as the product of the length value and the density value. Because of the arbitrary nature of 
Table I. Agecharacteristics of subjects examined, classified by subgroups of iris colour. One hundred and forty-seven subjects were not classified. S.D. denotes standard deviation.

\begin{tabular}{lccrr}
\hline Iris & Number of & \multicolumn{3}{c}{ Age (Years) } \\
Colour & Subjects & Mean & S.D. & Range \\
\hline Blue/Grey & 245 & 49.5 & 19.1 & $12-90$ \\
Brown/Green & 158 & 45.0 & 17.8 & $6-88$ \\
(All) & 550 & 47.3 & 18.7 & $6-90$ \\
\hline
\end{tabular}

Table II. Prevalence of Hudson-Stahli line in the eyes of the population studied, classified by iris colour. Percentages represent the proportion within a given subgroup of iris colour (across the rows).

\begin{tabular}{|c|c|c|c|c|}
\hline \multirow[b]{2}{*}{$\begin{array}{l}\text { Iris } \\
\text { Colour }\end{array}$} & \multirow[b]{2}{*}{$\begin{array}{c}\text { Number of } \\
\text { Subjects }\end{array}$} & \multicolumn{3}{|c|}{ Hudson-Stahli Line } \\
\hline & & $\begin{array}{l}f \text { Absent } \\
\text { both eyes }\end{array}$ & $\begin{array}{l}\text { Present } \\
\text { one eye }\end{array}$ & $\begin{array}{c}\text { Present } \\
\text { both eyes }\end{array}$ \\
\hline $\begin{array}{l}\text { Blue/Grey } \\
\text { Brown// }\end{array}$ & 245 & $83(34 \%)$ & $8(3 \%)$ & $154(63 \%)$ \\
\hline Green & 158 & $40(25 \%)$ & $8(5 \%)$ & $110(70 \%)$ \\
\hline (All) & 550 & $170(31 \%)$ & $23(4 \%)$ & $357(65 \%)$ \\
\hline
\end{tabular}

Table III. The length grading of Hudson-Stahli lines in 496 subjects with lines of equal density (where present in the right and left eyes). The number of subjects within each combination of right and left eye gradings is presented; those values on the line of identity are underlined.

Brackets indicate values in which discordance of density is forced by the presence of a line in one eye only.

\begin{tabular}{lccccr}
\hline & \multicolumn{4}{c}{ Length grading in right eye } \\
\cline { 3 - 6 } & & 0 & $<\frac{1}{4}$ & $\frac{1}{4}-\frac{1}{2}$ & $>\frac{1}{2}$ \\
\hline Length & 0 & $\frac{170}{(7)}$ & $(4)$ & $(2)$ & $(2)$ \\
grading & $<\frac{1}{4}$ & $\frac{41}{10}$ & 79 & 3 \\
in left & $\frac{1}{4}-\frac{1}{2}$ & $(7)$ & $\frac{39}{15}$ & 175 \\
eye & $>\frac{1}{2}$ & - & 2 & 15 & $\underline{175}$ \\
\hline
\end{tabular}

Table IV. The density grading of Hudson-Stahli lines in 513 subjects with lines of equal length (where present in the right and left eyes). The number of subjects within each combination of right and left eye gradings is presented; those values on the line of identity are underlined.

Brackets indicate values in which discordance of length is forced by the presence of a line in one eye only.

\begin{tabular}{lrrrrr}
\hline & & \multicolumn{4}{c}{ Density grading in right eye } \\
\cline { 3 - 6 } & & 0 & $1+$ & $2+$ & $3+$ \\
\hline Density & 0 & $\underline{170}$ & $(8)$ & $(1)$ & - \\
grading & $1+$ & $(13)$ & $\frac{178}{31}$ & 21 & 3 \\
in left & $2+$ & $(1)$ & $\underline{61}$ & 8 \\
eye & $3+$ & - & - & & $\underline{16}$ \\
\hline
\end{tabular}

the categories for grading length and density, a decision was made not to apply statistical significance tests to the numerical gradings.

\section{Results}

The 550 subjects had ages ranging from 6 to 90 years, with a mean age of 47.3 years. The two subgroups of different iris colours had similar age ranges, although there was a significant small difference between the means (Table I; unpaired two-tail Student $t$ test, $\mathrm{P}<0.05)$.

In the whole group, a Hudson-Stahli line was present in both eyes of 357 subjects $(65$ per cent) and in one eye of a further 23 subjects ( 4 per cent). Although the line was slightly commoner in the brown/green subgroup of iris colour (Table II), this did not reach statistical significance (chi square $=3.76 ; 2$ degrees of freedom). Concordance between the length of line in right and left eyes (Table III) was found in 425 (86 per cent) out of 496 pairs of eyes within which the density was equal (when lines present in both eyes). The line was found to be longer in the right eye in thirty pairs ( 6 per cent) and shorter in forty-one pairs (8 per cent). Similarly, a concordance between right and left eyes with regard to density was seen in 425 (83.per cent) out of 513 subjects with lines-when present in both eyes - of equal length (Table IV). The density was greater in the right eye in 8 per cent ( 41 pairs) and the left eye in 9 per cent ( 47 pairs). In 78 per cent of eyes the combined 'length/density' scores were the same (Table V). The concordance holds true for subgroups of iris colour (Table VI).

The incidence of Hudson-Stahli line is agerelated, occurring in about 20 per cent of eyes of subjects under twenty years of age, this rising to over 80 per cent above the fifth decade (Table VII); this increase occurs in both subgroups of iris colour, although the incidence is notably greater in brown eyes than in blue eyes during the third to fifth decades.

In those eyes having a Hudson-Stahli line, the mean 'length/density' scores for brown eyes are, with the exception of one age group, greater than those for blue eyes (Table VII); again, this difference is most marked within the third and fourth decades. By reference to Table VII, the difference is readily attributa- 
Table V. The combined 'length/density' scores of Hudson-Stahli lines in 550 subjects. The number of subjects within each combination of right and left eye scorings is presented; those scores on the line of identity are underlined.

\begin{tabular}{|c|c|c|c|c|c|c|c|c|}
\hline & & \multicolumn{7}{|c|}{ Combined lengthidensity score in right eye } \\
\hline & & 0 & 1 & 2 & 3 & 4 & 6 & 9 \\
\hline & 0 & 170 & 4 & 2 & 2 & - & 1 & - \\
\hline Combined & 1 & 7 & $\underline{40}$ & 7 & 3 & - & - & - \\
\hline Length/ & 2 & 6 & $\overline{11}$ & $\underline{36}$ & 7 & 3 & 2 & - \\
\hline Density & 3 & - & - & 6 & $\underline{105}$ & 2 & 13 & 3 \\
\hline score in & 4 & 1 & - & - & 2 & $\underline{3}$ & 1 & - \\
\hline \multirow[t]{2}{*}{ left eye } & 6 & - & 2 & . 3 & 23 & $\overline{5}$ & $\underline{58}$ & 6 \\
\hline & 9 & $-\cdots$ & - & - & - & - & $\overline{1}$ & 15 \\
\hline
\end{tabular}

Table VI. Proportion of subjects demonstrating concordance or discordance of the Hudson-Stahli line in right $(R)$ and left $(L)$ eyes. Data classified by iris colour and by length grading, density grading or 'length/density' scores.

\begin{tabular}{llccc}
\hline & & & Iris colours \\
\cline { 3 - 4 } Gradings & & Blue/Grey & Brown/Green & All \\
\hline Length & No. & 216 & 145 & 496 \\
& $\mathrm{R}>\mathrm{L}$ & $16(7 \%)$ & $6(4 \%)$ & $30(6 \%)$ \\
& $\mathrm{R}=\mathrm{L}$ & $180(84 \%)$ & $128(88 \%)$ & $425(86 \%)$ \\
Density & $\mathrm{R}<\mathrm{L}$ & $20(9 \%)$ & $11(8 \%)$ & $41(8 \%)$ \\
& $\mathrm{No}$ & 223 & 151 & 513 \\
& $\mathrm{R}>\mathrm{L}$ & $20(9 \%)$ & $13(9 \%)$ & $41(8 \%)$ \\
Length and & $\mathrm{R}=\mathrm{L}$ & $180(81 \%)$ & $128(84 \%)$ & $425(83 \%)$ \\
Density & $\mathrm{R}<\mathrm{L}$ & $23(10 \%)$ & $10(7 \%)$ & $47(9 \%)$ \\
& $\mathrm{N}$. & 245 & 158 & 550 \\
& $\mathrm{R}>\mathrm{L}$ & $30(12 \%)$ & $14(9 \%)$ & $56(10 \%)$ \\
& $\mathrm{R}=\mathrm{L}$ & $180(74 \%)$ & $128(81 \%)$ & $427(78 \%)$ \\
& $\mathrm{R}<\mathrm{L}$ & $35(14 \%)$ & $16(10 \%)$ & $67(12 \%)$ \\
\hline
\end{tabular}

Table VII. Incidence of Hudson-Stahli line classified by age and iris colour. The mean values for scoring of length, density and combined 'length/density' are also presented.

\begin{tabular}{|c|c|c|c|c|c|c|c|c|c|c|}
\hline & \multirow[b]{2}{*}{$\begin{array}{l}\text { Iris } \\
\text { Colour }\end{array}$} & \multicolumn{9}{|c|}{ Age group (years) } \\
\hline & & $<20$ & $20-29$ & $30-39$ & $40-49$ & $50-59$ & $60-69$ & $70-79$ & $\begin{array}{l}80 \text { or } \\
\text { more }\end{array}$ & All \\
\hline $\begin{array}{l}\text { Proportion of } \\
\text { involved eyes }\end{array}$ & $\begin{array}{l}\text { Blue/Grey } \\
\text { Brown/Green } \\
\text { All subjects. }\end{array}$ & $\begin{array}{c}4 / 22 \\
5 / 20 \\
12 / 60\end{array}$ & $\begin{array}{c}26 / 76 \\
24 / 42 \\
70 / 180\end{array}$ & $\begin{array}{c}29 / 72 \\
51 / 76 \\
102 / 186\end{array}$ & $\begin{array}{c}42 / 64 \\
51 / 62 \\
120 / 162\end{array}$ & $\begin{array}{c}79 / 98 \\
37 / 44 \\
166 / 202\end{array}$ & $\begin{array}{c}58 / 70 \\
28 / 38 \\
132 / 162\end{array}$ & $\begin{array}{c}58 / 66 \\
20 / 22 \\
98 / 108\end{array}$ & $\begin{array}{l}20 / 22 \\
12 / 12 \\
38 / 40\end{array}$ & $\begin{array}{c}316 / 490 \\
228 / 316 \\
737 / 1100\end{array}$ \\
\hline $\begin{array}{l}\text { Incidence } \\
(\%) \text { of eye } \\
\text { involvement }\end{array}$ & $\begin{array}{l}\text { Blue/Grey } \\
\text { Brown/Green } \\
\text { All subjects }\end{array}$ & $\begin{array}{l}18 \% \\
25 \% \\
20 \%\end{array}$ & $\begin{array}{l}35 \% \\
57 \% \\
39 \%\end{array}$ & $\begin{array}{l}40 \% \\
67 \% \\
56 \%\end{array}$ & $\begin{array}{l}66 \% \\
82 \% \\
74 \%\end{array}$ & $\begin{array}{l}79 \% \\
84 \% \\
82 \%\end{array}$ & $\begin{array}{l}83 \% \\
74 \% \\
81 \%\end{array}$ & $\begin{array}{l}88 \% \\
91 \% \\
91 \%\end{array}$ & $\begin{array}{c}91 \% \\
100 \% \\
95 \%\end{array}$ & $\begin{array}{l}64 \% \\
72 \% \\
67 \%\end{array}$ \\
\hline $\begin{array}{l}\text { Mean 'length/ } \\
\text { density' score } \\
\text { within } \\
\text { involved eyes }\end{array}$ & $\begin{array}{l}\text { Blue/Grey } \\
\text { Brown/Green }\end{array}$ & $\begin{array}{l}1.50 \\
1.80\end{array}$ & $\begin{array}{l}1.65 \\
2.58\end{array}$ & $\begin{array}{l}1.79 \\
3.41\end{array}$ & $\begin{array}{l}2.83 \\
3.02\end{array}$ & $\begin{array}{l}3.80 \\
4.41\end{array}$ & $\begin{array}{l}4.19 \\
5.14\end{array}$ & $\begin{array}{l}3.71 \\
5.00\end{array}$ & $\begin{array}{l}4.05 \\
2.92\end{array}$ & $\begin{array}{l}3.35 \\
3.69\end{array}$ \\
\hline $\begin{array}{l}\text { Mean length } \\
\text { grading within } \\
\text { involved eyes }\end{array}$ & $\begin{array}{l}\text { Blue/Grey } \\
\text { Brown/Green }\end{array}$ & $\begin{array}{l}1.50 \\
1.80\end{array}$ & $\begin{array}{l}1.73 \\
2.58\end{array}$ & $\begin{array}{l}1.69 \\
2.49\end{array}$ & $\begin{array}{l}2.40 \\
2.51\end{array}$ & $\begin{array}{l}2.63 \\
2.84\end{array}$ & $\begin{array}{l}2.62 \\
2.79\end{array}$ & $\begin{array}{l}2.47 \\
2.80\end{array}$ & $\begin{array}{l}2.70 \\
2.67\end{array}$ & $\begin{array}{l}2.26 \\
2.61\end{array}$ \\
\hline $\begin{array}{l}\text { Mean density } \\
\text { grading within } \\
\text { involved eyes }\end{array}$ & $\begin{array}{l}\text { Blue/Grey } \\
\text { Brown/Green }\end{array}$ & $\begin{array}{l}1.00 \\
1.00\end{array}$ & $\begin{array}{l}1.08 \\
1.00\end{array}$ & $\begin{array}{l}1.07 \\
1.31\end{array}$ & $\begin{array}{l}1.17 \\
1.18\end{array}$ & $\begin{array}{l}1.41 \\
1.54\end{array}$ & $\begin{array}{l}1.55 \\
1.79\end{array}$ & $\begin{array}{l}1.45 \\
1.75\end{array}$ & $\begin{array}{l}1.50 \\
1.08\end{array}$ & $\begin{array}{l}1.35 \\
1.36\end{array}$ \\
\hline
\end{tabular}


ble to a difference of lengths of the lines, rather than densities: Brown eyes tend to have longer lines (higher mean length scores), particularly in the third and fourth decades of life.

\section{Discussion}

Whilst it must be recognised that there is possibly an unintentional bias within the sample of subjects studied, the sample being drawn from an Accident and Emergency department, there was not any marked trend within the age distribution of those sampled.

The observed prevalence of 65 per cent with bilateral and a further 4 per cent with unilateral Hudson-Stahli line in the population studied is in agreement with works by other authors suggesting that the line is common, even being found in childhood $;^{2}$ in contrast, the incidence of 29 per cent recorded by Norn in a sample of 700 patients appears low when compared with the present results. ${ }^{8}$ The increasing incidence of Hudson-Stahli line with age is suggested by Gass, ${ }^{2}$. and documented by Norn. ${ }^{8}$ The finding of an 80 per cent to 90 per cent incidence in the sixth decade and beyond, whilst contrasting the 44 per cent incidence of Norn, is commensurate with the clinical estimates of Gass (greater than three-quarters of the elderly) and with the pathological studies on corneas (iron deposits being present in 59/62 specimensRef 2); the decreased incidence observed by Norn in the eighth and ninth decades ${ }^{8}$ has not been observed within the present study.
The apparent disparity between the results of the present study and that of Norn ${ }^{8}$ is not irresolvable: In the present study, those lines in which the density was graded as 'faint' formed, in general, a 1-2 mm broad zone of faint brown pigmentation and only rarely formed a distinct line; indeed, we consider this form of pigmentation to be the simplest type of Hudson-Stahli 'line' and would be better known as the Hudson-Stahli zone. ${ }^{9}$ It is probable that such eyes were not included in the work of Norn, in which he illustrates only clearly defined lines. If those eyes classified as having 'faint' lines are omitted from the results of the present study, the new incidences are of similar magnitude to those of Norn (Table VIII); moreover, it is notable that these new figures derived from the present study also show a very small decline of incidences in the eighth and ninth decades, as described by Norn.

There have not been any reports of the incidence of Hudson-Stahli line in eyes with different degrees of iris pigmentation. The present study, whilst demonstrating the trend of increasing incidence with age within all groups of iris colour, also suggests that the incidence is slightly higher in brown and green eyes (irrespective of age), this difference being particularly marked in the younger decades. It is possible that fine deposits of melanin spreading centrally onto the cornea from areas of limbal melanosis might be contributing indistinguishably to the Hudson-

Table VIII. Incidence of Hudson-Stahli line with different densities, classified by age and iris colour. Figures are presented for those lines judged to be 'faint', and for those judged to be 'moderate' or 'dense'. Figures from a study by norn (8) are included for comparison.

Age group (years)

\begin{tabular}{|c|c|c|c|c|c|c|c|c|c|c|}
\hline \multirow{2}{*}{$\begin{array}{l}\text { Iris } \\
\text { Colour }\end{array}$} & \multirow{2}{*}{$\begin{array}{l}\text { Density } \\
\text { of line }\end{array}$} & \multicolumn{9}{|c|}{ Age group (years) } \\
\hline & & $<20$ & $20-29$ & $30-39$ & $40-49$ & $50-59$ & $60-69$ & $70-79$ & 80 or more & All \\
\hline \multirow[t]{4}{*}{ Blue/Grey } & Faint & $4 / 22$ & $24 / 76$ & $27 / 72$ & $36 / 64$ & $50 / 98$ & $30 / 70$ & $38 / 66$ & $12 / 22$ & $221 / 490$ \\
\hline & & $(18 \%)$ & $(32 \%)$ & $(38 \%)$ & $(56 \%)$ & $(51 \%)$ & $(43 \%)$ & $(58 \%)$ & $(55 \%)$ & $(45 \%)$ \\
\hline & Moderate & $0 / 22$ & $2 / 76$ & $2 / 72$ & $6 / 64$ & $29 / 98$ & $28 / 70$ & $20 / 66$ & $8 / 22$ & $95 / 490$ \\
\hline & + dense & $(0 \%)$ & $(3 \%)$ & $(3 \%)$ & $(9 \%)$ & $(30 \%)$ & $(40 \%)$ & $(30 \%)$ & $(36 \%)$ & $(19 \%)$ \\
\hline \multirow[t]{4}{*}{ Brown/Green } & Faint & $5 / 20$ & $24 / 42$ & $36 / 76$ & $42 / 62$ & $21 / 44$ & $14 / 38$ & $11 / 22$ & $11 / 12$ & $164 / 316$ \\
\hline & & $(25 \%)$ & $(57 \%)$ & $(47 \%)$ & $(68 \%)$ & $(48 \%)$ & $(37 \%)$ & $(50 \%)$ & $(92 \%)$ & $(52 \%)$ \\
\hline & Moderate & $0 / 20$ & $0 / 42$ & $15 / 76$ & $9 / 62$ & $16 / 44$ & $14 / 38$ & $9 / 22$ & $1 / 12$ & $64 / 316$ \\
\hline & + dense & $(0 \%)$ & $(0 \%)$ & $(20 \%)$ & $(15 \%)$ & $(36 \%)$ & $(37 \%)$ & $(41 \%)$ & $(8 \%)$ & $(20 \%)$ \\
\hline \multirow[t]{6}{*}{ All subjects } & Faint & $12 / 60$ & $66 / 180$ & $84 / 186$ & $99 / 162$ & $94 / 202$ & $66 / 162$ & $57 / 108$ & $23 / 40$ & $501 / 1100$ \\
\hline & & $(20 \%)$ & $(37 \%)$ & $(45 \%)$ & $(61 \%)$ & $(47 \%)$ & $(41 \%)$ & $(53 \%)$ & $(58 \%)$ & $(46 \%)$ \\
\hline & Moderate & $0 / 60$ & $4 / 180$ & $18 / 186$ & $21 / 162$ & $71 / 202$ & $66 / 162$ & $41 / 108$ & $15 / 40$ & $236 / 1100$ \\
\hline & + dense & $(0 \%)$ & $(2 \%)$ & $(10 \%)$ & $(13 \%)$ & $(35 \%)$ & $(41 \%)$ & $(38 \%)$ & $(38 \%)$ & $(21 \%)$ \\
\hline & Norn's & $1 \%$ & $11 \%$ & $14 \%$ & $22 \%$ & $31 \%$ & $44 \%$ & $33 \%$ & $31 \%$ & $29 \%$ \\
\hline & Data & & & & & & & & & \\
\hline
\end{tabular}


Stahli line in heavily pigmented eyes..$^{7,10,11} \mathrm{It}$ is most unlikely that the difference is artefactual as a result of slit-lamp biomicroscopic examination against different colours of iris; the more pigmented brown and green irides tend to reduce, rather than enhance, the contrast of the yellow-brown Hudson-Stahli line.

The demonstration that the majority of people with Hudson-Stahli line have bilateral involvement, irrespective of their eye colour, is compatible with the observations of Norn. ${ }^{8}$ The high degree of concordance of either length or density in the right and the left eyes of a pair has not been previously reported and applies to all subgroups of iris colour. In addition, in those subjects with discordance of Hudson-Stahli line, there was no detectable bias in favour of either the right or the left eyes (Table VI), suggesting the absence of any systematic bias of examination techniques in the present study.

There would appear to be only one previous study of the density and the size of HudsonStahli line, ${ }^{8}$ the results from the present work being largely in agreement with those of Norn. Superimposed on an overall gradual rise of the mean density scores, there was a quite marked step-wise increase between the fifth and sixth decades in eyes of all colours (Table VII); a similar progressive increase in the density of the lines was reported by Norn although a small decline in density after the sixth decade is of doubtful significance. The length of the line has also been shown to increase with age in all eyes and, in addition, lengths are markedly greater in brown/green eyes of the third and fourth decades. Although both studies show increasing length of Hudson-Stahli line within affected eyes, there is a considerable disparity between the two; the mean lengths in the Norn study are between one-half and one-third of those in the present study. It is probable that Norn excluded the very finely branching ends of the lines from his measured lengths, whereas these were included in the estimates we made; evidence to support this suggestion is provided by the absence of ramifying lines amongst the morphological illustrations given by Norn.

\section{References}

${ }^{1}$ Hudson AC: A note on certain peculiar pigmentary markings in the cornea. Roy Lond Ophth Hosp Rep 1911, 18: 198-202.

${ }^{2}$ Gass JD: The iron lines of the superficial cornea. Hudson-Stahli line, Stocker's line and Fleischer's ring. Arch Ophthalmol 1964, 71: 34858.

${ }^{3}$ Iwamato T, DeVoe AG: Electron microscopical study of the Fleischer ring. Arch Ophthalmol 1976, 94: 1579-84.

${ }^{4}$ Ferry AP: A 'new' iron line of the superficial cornea. Occurrence in patients with filtering blebs. Arch Ophthalmol 1968, 79: 142-5.

${ }^{5}$ Norn MS: Hudson-Stahli's line of cornea. II. Aetiological studies. Acta Ophthalmol 1968, 46: 119-28.

${ }^{6}$ Barraquer-Somers E, Chan CC, Green WR: Corneal epithelial iron deposition. Ophthalmology 1983, 90: 729-34.

${ }^{7}$ Friedenwald JS, Wilder HC, Maumenee AE, Saunders TE, Keyes JEL, Hogan MJ, Owens WC, Owens EL: Ophthalmic Pathology: An atlas and textbook. WB Saunders, Philadelphia, 1952, pp 220-226.

${ }^{8}$ Norn MS: Hudson-Stahli's line of cornea. I. Incidence and morphology. Acta Ophthalmol 1968, 46: 106-18.

${ }^{9}$ Rose GE, Lavin MJ: The Hudson-Stahli line III: Observations on morphology, a critical review of aetiology and a unified theory for the formation of iron lines of the corneal epithelium. Eye (In Press).

${ }^{10}$ McCracken JS, Klintworth GK: Ultrastructural observations on experimentally produced melanin pigmentation of the corneal epithelium. Am J Pathol 1976, 85: 167-176.

11 Spencer WH: Ophthalmic Pathology. WB Saunders, Philadelphia, 1985, 3 Ed, pp 372-4 